\title{
Phytoremediation of Explosive-Contaminated Soils
}

\author{
Jeffrey D. Kiiskila • Padmini Das • Dibyendu Sarkar • \\ Rupali Datta
}

Published online: 14 March 2015

(C) Springer International Publishing AG 2015

\begin{abstract}
In order to select appropriate plant species for phytoremediation of explosive compounds, phytotoxicity, uptake proficiency, capability of the plant to degrade/transform the compounds, and several environmental factors need to be considered. The environmental factors comprise climatic attributes, soil type, the water environment, root penetration depth, contaminant kinetics, and bioavailability. Out of the plant species that have shown efficient TNT uptake, there are only a few that can do so in a variety of environments, which is imperative in case of contaminants that are widespread, such as TNT and RDX. The two most effective species for TNT uptake reported to date are Eurasian water milfoil, Myriophyllum spicatum and vetiver grass, Chrysopogon zizanioides. For RDX phytoremediation, reed canary grass, fox sedge, and rice have shown promise, although degradation of RDX in the plant tissue is limited. Over the past few decades, a considerable amount of information on phytotoxicity and metabolism of TNT and RDX in plants and microorganisms have been collected, which has led to the identification of potential plant species for use in TNT and RDX
\end{abstract}

This article is part of the Topical Collection on Land Pollution

J. D. Kiiskila $\cdot$ R. Datta $(\bowtie)$

Department of Biological Sciences, Michigan Technological

University, Houghton, MI 49931, USA

e-mail: rupdatta@mtu.edu

J. D. Kiiskila

e-mail: jdkiiski@mtu.edu

P. Das • D. Sarkar

Department of Earth and Environmental Studies,

Montclair State University, Montclair, NJ 07043, USA

P. Das

e-mail: dasp@mail.montclair.edu

D. Sarkar

e-mail: sarkard@mail.montclair.edu phytoremediation, as well as candidate genes for developing effective transgenic plants. Recent research has also revealed promising non-transgenic approaches, such as use of chaotropic agents for enhanced solubilization and uptake of TNT, which could prove to be practical and effective for military sites. Field trials of some of these promising new technologies are necessary for the development of effective, lowcost, and environmentally friendly phytoremediation of explosive-contaminated sites.

Keywords TNT $\cdot$ RDX $\cdot$ Phytoremediation $\cdot$ Plant metabolism $\cdot$ Detoxification $\cdot$ Biotechnology

\section{Introduction}

Explosive compounds have been utilized for numerous applications such as in military munitions, mining, and construction. The manufacture, utilization, and decommissioning of explosives has led to extensive environmental contamination [1]. Production facilities and training ranges serve as the most common sites for contamination, where explosive compounds and their transformed products are able to permeate the soil and leach into the groundwater. Major soil contaminants found in army depots, ammunition evaluation facilities, artillery ranges, and ordnance disposal sites include composition B (Comp B), which is a commonly used military formulation, consisting of the toxic explosive compounds 2,4,6-trinitrotoluene (TNT), hexahydro-1,3,5-trinitro-1,3,5-triazine (RDX), and octahydro-1,3,5,7-tetranitro-1,3,5,7-tetrazocine (HMX) [2]. Their recalcitrance to degradation, toxic, and mutagenic effects has made explosive contamination a matter of concern. In the USA, between closed sites and offshore areas, the Defense Science Board has specified that there could be more than 6 million hectares (15 million acres) contaminated with explosives [2]. Apart from the USA, there are a very large 
number of contaminated sites throughout Europe, Asia, and Africa, where local conflicts lead to large-scale burying of ordnance in the form of land mines [1].

Over the past decade, research has increasingly focused on developing ecologically viable, cost-effective, and reliable in situ remediation techniques and self-cleaning explosive formulations. One of the major challenges in developing a successful in situ bioengineered remediation technique lies in the limited bioavailability of TNT, resulting from the characteristic hydrophobicity of the nitroaromatic compounds (aqueous solubility of TNT is $101.5 \mathrm{mg} \mathrm{L}^{-1}$ at $25^{\circ} \mathrm{C}$ ) [3, 4]. Though the ability of microorganisms to breakdown a variety of xenobiotics has made the use of bioaugmentation seems promising, some studies reported that indigenous microbes frequently outcompete the foreign microbes, which results in limited success [5]. Plant-assisted degradation of xenobiotics through phytoremediation could offer an environmentally friendly, cost-effective technique for remediating explosive compounds. Certain plants have developed intricate detoxification systems to deal with explosives [2], which allow them to survive in areas with concentrations of these contaminants. Their root systems can take up the xenobiotics [2], while stabilizing the soils and minimizing the atmospheric release of contaminated dusts [6]. Plants offer additional benefits, as they could supply nutrients for the rhizosphere bacteria which may symbiotically aid in remediation, while the plants themselves would make monitoring of the site easier through tissue collection and even simple visualization [6]. The limitation of phytoremediation is that it is a time-consuming process. However, since explosive-contaminated sites are unusable, and given that such contamination usually covers large expanses of land, phytoremediation could be an appropriate technology for the remediation of explosive-contaminated sites [4]. This review highlights the recent progress made in developing effective phytoremediation techniques for soils contaminated with explosives such as TNT and RDX.

\section{Toxicity of Explosive Compounds}

Explosive compounds fall into three main classes: nitroaromatics, nitramines, and nitrate esters [2, 4]. While differentiated based on their formulae, explosive contaminants ubiquitously contain the nitro $\left(-\mathrm{NO}_{2}\right)$ functional groups.

\section{Nitroaromatics}

Nitroaromatic compounds are characterized by an aromatic ring having multiple nitro groups, sometimes referred to as aryl nitro groups. Historically, the most commonly used explosive compound is TNT. TNT consists structurally of toluene bound with three nitro groups, which deactivate the aromatic ring through electron withdrawal. This conformation makes electrophilic attack of the aromatic ring difficult, and as a result, TNT is highly recalcitrant to degradation by oxidation and hydrolysis [2]. In the soil, TNT forms covalent bonds with the functional groups of humic acid and other organic compounds making it unavailable biologically $[2,7$, $8]$. The octanol-water partition coefficients $\left(K_{\mathrm{OW}}\right)$, offer support to this concept, as they are higher in nitroaromatic compounds when compared to the other classes of explosive compounds [8] (Table 1).

Despite stopping TNT production in the USA in the mid1980s, contamination still largely exists from World Wars I and II $[9,10]$. Moreover, TNT is still used in certain US munitions [10]. Several studies have examined TNT toxicity in a variety of organisms. TNT was reported as the most toxic of the explosive contaminants through the mutatox and green algal bioassays [9] and has an $\mathrm{LD}_{50}$ of $795 \mathrm{mg} \mathrm{kg}^{-1}$ in rats [11]. In animals, exposure may lead to skin rashes, blood disorders, and organ damage or failure $[5,9]$. TNT has been defined as a frameshift mutagen through the Ames test [5], while the USEPA has classified it as a group $\mathrm{C}$ potential human carcinogen [10].

There are two similar nitroaromatic isomers known as 2,4and 2,6-dinitrotoluene, otherwise identified as DNTs, that differ from TNT, as they lack one of the three nitro groups. These compounds can result as byproducts of TNT production or transformation, though they have manufacturing use as intermediates in polyurethane assembly [9]. Both isomers express higher toxicity than TNT in in vivo studies $\left(\mathrm{LD}_{50}\right.$ in rat $=270$ and $180 \mathrm{mg} \mathrm{kg}^{-1}$, respectively) and are classified as group B human carcinogens [12]. There are numerous nitroaromatic compounds in addition to TNT and DNTs, though they are much less common. These compounds would include nitrobenzenes such as 1,3,5-trinitrobenzene (TNB) and isomers of monoaminodinitrotoluene (ADNT). In animal model experiments, 1,3,5-TNB toxicity was higher $\left(\mathrm{LD}_{50}\right.$ in rat= $284 \mathrm{mg} \mathrm{kg}^{-1}$ ) [13] than that of TNT [11]. Terrestrial plants have shown contradictory results for TNT and TBN toxicities, where TNT toxicity is greater with alfalfa (TNT $\mathrm{EC}_{50}=$ $93 \mathrm{mg} \mathrm{kg}^{-1}$ and $\mathrm{TNB} \mathrm{EC} \mathrm{E}_{50}=129 \mathrm{mg} \mathrm{kg}^{-1}$ ) and TNB toxicity is greater with Japanese millet, Echinochloa crusgalli (TNT $\mathrm{EC}_{50}=173 \mathrm{mg} \mathrm{kg}^{-1}$ and TNB $\mathrm{EC}_{50}=89 \mathrm{mg} \mathrm{kg}^{-1}$ ) [14]. In contrast, perennial ryegrass, Lolium perenne has shown little difference in the toxicities for these two compounds (TNT $\mathrm{EC}_{50}=86 \mathrm{mg} \mathrm{kg}^{-1}$ and $\mathrm{TNB} \mathrm{EC}_{50}=89 \mathrm{mg} \mathrm{kg}^{-1}$ ) [14]. In animals, ADNTs exhibit lower toxicity than the parent TNT

Table 1 Logarithm $K_{\mathrm{OW}}$ values for TNT; RDX; 2,4-DNT; and 2,6DNT (From Yoon et al. 2005 [8])

\begin{tabular}{lllll}
\hline & TNT & RDX & 2,4-DNT & $2,6-\mathrm{DNT}$ \\
\hline $\log K_{\text {OW }}$ & $1.6-1.84$ & $0.81-0.87$ & 1.98 & $1.9-2.10$ \\
\hline
\end{tabular}


compound $\left(\mathrm{LD}_{50}\right.$ in rat $=959$ and $1522 \mathrm{mg} \mathrm{kg}^{-1}$ for 4-ADNT and 2-ADNT, respectively) [15].

\section{Nitroamines}

Nitroamine compounds differ from nitroaromatics in that they contain N-nitro groups. Prominent among this class of explosives is RDX, currently, the most widely used explosive compound [5] Frequently used in explosive mixtures with TNT, RDX can be found in ordnance or land mines, as well as in the familiar plastic explosive, composition 4 [4]. The name RDX has an ambiguous lineage, but is most frequently sourced to abbreviate Royal Demolition Explosive or Research Department Explosive [4, 5].

RDX has a lower $K_{\mathrm{OW}}$ value (Table 1 ) and therefore does not firmly bind with the soil, making it more readily available and highly mobile [8]. For this reason, RDX contamination can spread more deeply into the soil and has a superior ability to leach into sources of drinking water. While toxic to both animals and plants, RDX is known for targeting the central nervous system when inhaled, resulting in convulsions and loss of consciousness. Furthermore, this compound has been shown to have adverse effects on the gastrointestinal and renal systems [16]. It has been used previously as a rat poison [5]. USEPA has it classified as a potential human carcinogen.

In plants, RDX has been shown to suppress growth, though phytotoxicity is much lower when compared to TNT [5]. RDX is additionally known for its ability to translocate within plants, and therefore these compounds can accumulate in various parts of the plants. Despite its ability to translocate, RDX has been reported to have lower toxicity than TNT [5].

\section{Candidates for TNT and RDX Phytoremediation}

Aspects to be considered when selecting plant species for TNT and RDX phytoremediation include phytotoxicity, uptake proficiency, capability of the plant to degrade/transform the contaminant and various environmental factors. The environmental factors comprise climatic attributes along with plant growth conditions. Furthermore, the soil type and the water environment play major roles in plant growth, root penetration depth, contaminant kinetics, and bioavailability. Soil type is a major consideration for choosing candidates for TNT and RDX phytoremediation, because various soil components impact plant availability, and therefore, phytotoxicity. Plant availability of TNT in soils is mainly controlled by soil properties such as clay and organic carbon content. Generally, clay and organic carbon content show an inverse correlation with uptake of TNT by plants. TNT shows higher affinity to sorb on clay-rich soils and sediments compared to RDX [17]. Also, both dissolved (DOM) and particulate (POM) organic carbon associate with munitions [18]. Several reports have shown that sorption and retention of TNT increases with increased organic carbon in soil $[18,19]$. However, other reports also show that the presence of organic carbon has either no impact or a negative impact on sorption of TNT and $\operatorname{RDX}[17,20]$. Hence, further studies are necessary to fully illustrate the mechanism involved in sorption of munitions by organic carbon.

Screening for phytoremediation candidate plants using toxicity parameters, uptake potential, and enzyme activity is commonly practiced [21]. Out of the plant species that have shown efficient TNT uptake, there are few that can do so in a variety of environments required by such a wide-spread contaminant. An early study showed that grasses are promising candidates, including brome grass, switch grass, alfalfa, oat, and wheat [9]. The two most effective species for TNT uptake to date are Eurasian water milfoil, Myriophyllum spicatum [22] and vetiver grass, Chrysopogon zizanioides [23] (Table 2).

The use of phytoremediation presents additional challenges with RDX, since plants tend to accumulate this compound in their shoot tissues [25]. The mobility of RDX would indicate that densely rooted plants with a longer reach may be more applicable. Only a few species have been explicitly indicated for their potential in RDX remediation, including reed canary grass, Phalaris arundinaceae; fox sedge, Carex vulpinoidea; and rice, Oryza sativa (Table 2) $[5,25,26]$.

\section{TNT Phytoremediation}

Early investigations from the Iowa Army Ammunition Plant (IAAP) near Burlington, IA studied nine species for their potential use in the phytoremediation of explosives. Among the plants with the most effective TNT uptake was the reed canary grass, along with coontail, Ceratophyllum demersum L. and American pondweed, Potamogeton nodosus Poir. Under temperature-controlled conditions at $25^{\circ} \mathrm{C}$, these plants were shown to remove $94-100 \%$ TNT over a 10 -day period while the control plants removed $62-85 \%$. Tissue analyses showed metabolites of TNT detoxification along with other unidentified compounds [26]. The aquatic plant, M. spicatum was investigated for its TNT uptake and detoxification abilities at the Alabama Army Ammunition Plant in Childersburg, AL. It was reported that M. spicatum had a high potential for TNT with a maximum uptake of $1.6 \mathrm{mg} \mathrm{g}^{-1}$ of wet weight (Table 2) [22].

Through a greenhouse soil study, eleven species were evaluated with 10, 100, and $500 \mathrm{mg} \mathrm{kg}^{-1}$ TNT treatments. The common bean (Phaseolus vulgaris), alfalfa (Medicago sativa), and wheat (Triticum aestivum) were chosen for their prior demonstration of nitroaromatic compound uptake [27]. Additionally, a lupin species, Lupinus angustifolius and Phacelia seicea were selected for soil-improvement capabilities. This study showed that while all the species were able to remove nitroaromatic compounds from the soil, only 
Table 2 Relative effectiveness of candidate plants for TNT and RDX phytoremediation; including experiment time (days), planting density (g L ${ }^{-1}$ ), explosive concentration (mM, unless otherwise indicated), and maximum uptake ( $\mathrm{mg} \mathrm{g}^{-1}$, unless otherwise indicated)

\begin{tabular}{|c|c|c|c|c|c|}
\hline Plant species & Time (days) & Density & Concentration & Uptake ( $\left.\mathrm{mg} \mathrm{g}^{-1}\right)$ & Reference \\
\hline Vetiver grass C. zizanioides & 8 & $39 \mathrm{~g} \mathrm{~L}^{-1}$ & $0.18 \mathrm{mM}$ TNT & 1.03 wet & Makris et al. 2007 [23] \\
\hline \multirow[t]{2}{*}{ Eurasian water milfoil $M$. spicatum } & 5 & $33.3 \mathrm{~g} \mathrm{~L}^{-1}$ & $0.50 \mathrm{mM}$ TNT & 0.29 wet & Pavlostathis et al. 1998 [24] \\
\hline & 7 & $50 \mathrm{~g} \mathrm{~L}^{-1}$ & $0.35 \mathrm{mM}$ TNT & 1.6 wet & Hughes et al. 1997 [22] \\
\hline Soybean G. $\max$ & 3 & NA & $0.10 \mathrm{mM}$ TNT & 0.21 wet & Adamia et al. 2006 [21] \\
\hline Barley H. sativum & 3 & NA & $0.10 \mathrm{mM}$ TNT & 0.10 wet & Adamia et al. 2006 [21] \\
\hline Alfalfa $M$. sativa & 3 & NA & $0.10 \mathrm{mM}$ TNT & 0.08 wet & Adamia et al. 2006 [21] \\
\hline Chickpea $C$. arietinum & 3 & NA & $0.10 \mathrm{mM}$ TNT & 0.15 wet & Adamia et al. 2006 [21] \\
\hline PeaP. sativum & 3 & NA & $0.10 \mathrm{mM}$ TNT & 0.16 wet & Adamia et al. 2006 [21] \\
\hline Ryegrass L. multiflorum & 3 & NA & $0.10 \mathrm{mM}$ TNT & 0.16 wet & Adamia et al. 2006 [21] \\
\hline Sunflower $H$. annuus & 3 & NA & $0.10 \mathrm{mM}$ TNT & 0.06 wet & Adamia et al. 2006 [21] \\
\hline Maize $Z$. mays & 3 & NA & $0.10 \mathrm{mM}$ TNT & 0.09 wet & Adamia et al. 2006 [21] \\
\hline Rice $O$. sativa & 40 & NA & 0-2000 mg kg ${ }^{-1} \mathrm{RDX}$ & $\sim 30-80$ dry & Vila et al. 2007 [25] \\
\hline Reed canary grass $P$. arundinaceae & 10 & NA & $12.8 \mathrm{mM}$ RDX & $27 \%$ & Best et al. 1997 [26] \\
\hline Fox sedge $C$. vulpinoidea & 10 & NA & $12.8 \mathrm{mM}$ RDX & $26 \%$ & Best et al. 1997 [26] \\
\hline
\end{tabular}

P. vulgaris was able to do so at $500 \mathrm{mg} \mathrm{kg}^{-1}$. P. vulgaris and wheat showed similar uptake potential for nitroaromatics and collected these compounds at similar concentration in the root tissues (Table 2) [27].

In a more recent study, a number of agriculturally and ornamentally significant plants were investigated for their ability to remediate TNT. Soybean (Glycine max), barley (Hordeum sativum), alfalfa (M. sativa), chickpea (Cicer arietinum), pea (Pisum sativum), ryegrass (Lolium multiflorum), sunflower (Helianthus annuus), and maize (Zea mays) species were included in this study (Table 2) [21]. Soybean demonstrated the most potential with a maximum uptake of $0.21 \mathrm{mg} \mathrm{g}^{-1}$, and demonstrated a high nitroreductase activity. Interestingly, a majority of soybeans' metabolites accumulated in the shoot tissues [21].

Vetiver grass is a subtropical species with many unique properties. This species of grass has a large biomass with the potential for growing larger than $2 \mathrm{~m}$ in height and contains a dense root system with the potential for reaching below $3 \mathrm{~m}$ underground [28]. Vetiver is a known hyperaccumulator of lead and has the potential for remediating a variety of other heavy metals as well $[29,30]$. It is also reported to have a high affinity for organic contaminants such as polycyclic aromatic hydrocarbons and explosive compounds [23, 31]. From its adaptability to multiple environments to its affinity for various organic contaminants, vetiver serves as a prime candidate for the phytoremediation of explosives.

In recent studies vetiver grass has shown high affinity for TNT when treated under hydroponic conditions. The maximum uptake was reported at $1.03 \mathrm{mg} \mathrm{g}^{-1}$ wet weight, which would place vetiver among the top two species alongside
M. spicatum, since all of the other investigated species have shown significantly lower values [23]. However, vetiver was being treated with about $0.18 \mathrm{mM}$ TNT at a planting density of $39 \mathrm{~g} \mathrm{~L}^{-1}$ (Table 2) [23], as compared to M. spicatum with $0.35 \mathrm{mM}$ at a planting density of $50 \mathrm{~g} \mathrm{~L}^{-1}$ [22]. This could suggest that vetiver is on par with M. spicatum in being the best suited candidate for remediating TNT.

\section{RDX Phytoremediation}

For RDX phytoremediation, nine plant species were investigated at the IAAP for their uptake potential with RDX [26]. These plants showed much less potential for RDX uptake. It was noted that RDX uptake was significantly slower than that of TNT. However, there were a few species that did show uptake potential. Out of these species, the reed canary grass was the most successful as it was able to uptake $27 \%$ of the initial RDX, while fox sedge was close behind at $26 \%$ (Table 2) [26].

Rice was examined both for toxicity and uptake potential with RDX by Vila et al. [25]. Rice growth remained unaffected at RDX concentration of $2000 \mathrm{mg} \mathrm{kg}^{-1}$, although there was necrosis in the extremities along with a decrease in total chlorophyll when RDX exceeded $500 \mathrm{mg} \mathrm{kg}^{-1}$. It was determined through ${ }^{14} \mathrm{C}$-radiolabeling that $89 \%$ of the RDX taken up by the plants was translocated to the shoot tissues, with a reported $90 \%$ moving to the extremities. However, there was little evidence of transformation [25], so rice tissue would likely have to undergo downstream processing after harvesting to avoid bioaccumulation. 


\section{Uptake and Metabolism of Explosives}

Xenobiotics are taken up through the roots or the stomata of the exposed plants. Early studies summarized by Yoon et al. [8] discovered a predictive relationship between uptake rates and translocation based on the physicochemical properties of such compounds. Logarithm $K_{\mathrm{OW}}\left(\log K_{\mathrm{OW}}\right)$ of a particular compound is often related to the root concentration factor (RCF), which is defined as concentration sorbed through the roots/concentration in the aqueous surroundings [8]. Another relationship was also discovered, which involves the $\log K_{\mathrm{OW}}$ and the transpiration stream concentration factor (TSCF), defined as concentration in the transpiration stream/ concentration in the aqueous surroundings [8]. Hydrophobic compounds with $\log K_{\mathrm{OW}}$ values greater than 3.8 are not translocated through the plant as they firmly bind within root tissues, while hydrophilic compounds with values less than 1.8 are unable to pass through the membranes of the root tissues $[8,28]$. These relationships are represented in Eqs. 1 and 2 [32]:

$\log (\mathrm{RCF}-0.82)=0.77 \log K_{\mathrm{OW}}-1.52$

$\mathrm{TSCF}=0.756^{\left(-\left(\log K_{\mathrm{OW}}-2.50\right) \frac{2}{2.58}\right)}$

Explosives undergo a three phase detoxification process in plants [8], which culminates in requisition of the metabolites into their biomass through a process known as sequestration. This sort of compartmentalization is often referred to as the green liver model, giving plants the ability to isolate the xenobiotics from other cellular constituents, thus minimizing the deleterious effects [8]. In general, this process begins at phase I with a transformation of the contaminant through reactions such as reduction, oxidation, and hydrolytic or photolytic reactions (Fig. 1). This makes the contaminant more responsive by replacing non-reactive groups with polar ones including hydroxyl $(-\mathrm{OH})$, amino $\left(-\mathrm{NH}_{2}\right)$, or sulfhydryl $(-\mathrm{SH})$ groups. This is followed by phase II where the new reactive group of the transformed product is conjugated in the cytosol by transferases. Conjugation involves the paring of hydrophilic molecules such as carbohydrates, amino acids, or glutathione with the appropriate reactive groups, which essentially makes the transformed product more soluble $[4,5,8]$. For example, Dglucose can bind with hydroxyl, amino, sulfhydryl, and even carboxyl $(-\mathrm{COOH})$ groups, while malonate is primarily known for conjugating with hydroxyl and amino groups [5]. In most cases, these conjugates are much less toxic than the parent compounds. The conjugates undergo phase III, where they are sequestered in particular cellular compartments such as the vacuole for soluble conjugates or to the cell wall for bound conjugates which can be incorporated into the wall by way of binding to lignin, hemicellulose, or other components [4, 8] (Fig. 1).

\section{Metabolism of TNT}

The phases I and II processes of TNT detoxification are well characterized in plants, primarily in parrot feather, Myriophyllum aquaticum and Arabidopsis thaliana, along with other species. Phase I frequently comprises reductive transformation of the nitro groups through nicotinamide coenzyme equivalents. This involves the initial formation of nitroso $(-\mathrm{NH}-\mathrm{OH})$ intermediates, which would include the 2- and 4-isomers of hydroxylaminodinitrotoluene (HADNT). HADNTs can directly enter phase II of detoxification or undergo a number of secondary transformations. Subsequent reduction results in 2- or 4-ADNT which are known for being more stable than the HADNTs. In addition to ADNTs, the HADNTs could theoretically be transformed into 2,4- and 2, 6-isomers of diaminonitrotoluene, or 2,4,6-trinitrotoluene. In either scenario, the amino groups would become highly electronegative and therefore reactive by way of forcing the electrons back into the aromatic ring. Alternatively, the newly reactive HADNTs could be abiotically oxidized to form the azoxy isomers 4,4',6,6'-tetranitro-2,2'-azoxytoluene and 2,2', $6,6^{\prime}$-tetranitro-4,4'-azoxytoluene, which are dimers formed between two of the compounds [33, 34] (Fig. 1). In addition to the reductive means, earlier studies found evidence of oxidative transformation of TNT in parrot feather root tissues [35]. Multiple alkyl hydroxylations were thought to be responsible in the formation of 2-amino-4,6-dinitrobenzoic acid, as well as ring hydroxylation of TNT in the formation of 2,4dinitro-6-hydroxybenzyl alcohol and isomers of dinitrohydroxytoluene [35]. Oxidative transformation might play a role in TNT detoxification to some extent, though the amount of supporting information for reductive transformation is overwhelming.

Techniques such as serial analysis of gene expression (SAGE) have been used to develop transcriptome profiles of Arabidopsis and other species when exposed to TNT, which identified a number of genes responsible at various stages of detoxification. Some of the candidate enzymes for phase I transformations have included a number of reductases, cytochrome P450s (P450s), and peroxidases. The presence of $\mathrm{P} 450 \mathrm{~s}$ points to oxidative transformation, though it has been indicated between the reductive metabolites and high rate of reaction that routine oxidation seems unlikely [36]. It has also been reported that the nitroreductases often contain a noncovalently bound flavin mononucleotide (FMN) as an oxidation-reduction cofactor [16]. More promising are homo$\operatorname{logs}$ to the old yellow enzyme (OYE) in yeast, the oxophytodienoate reductase (OPR) family, which are NADPH-dependent flavoproteins. These enzymes have been noted for their similarity to nitrate ester reductases which are 
Fig. 1 Proposed detoxification pathway of the explosive TNT in plants. Phase I of TNT detoxification involves the transformation via nitrosodinitrotoluene (NO-DNT) to 2and 4-hydroxydinitrotoluene (HADNT) isomers. Phase II involves the conjugation of the transformed intermediates to endogenous plant compounds, including sugars. In phase III, the conjugates are sequestered into the plant biomass, possibly by incorporation into plant cell walls or compartmentalization into vacuoles. (From Rylott and Bruce 2009 [4])

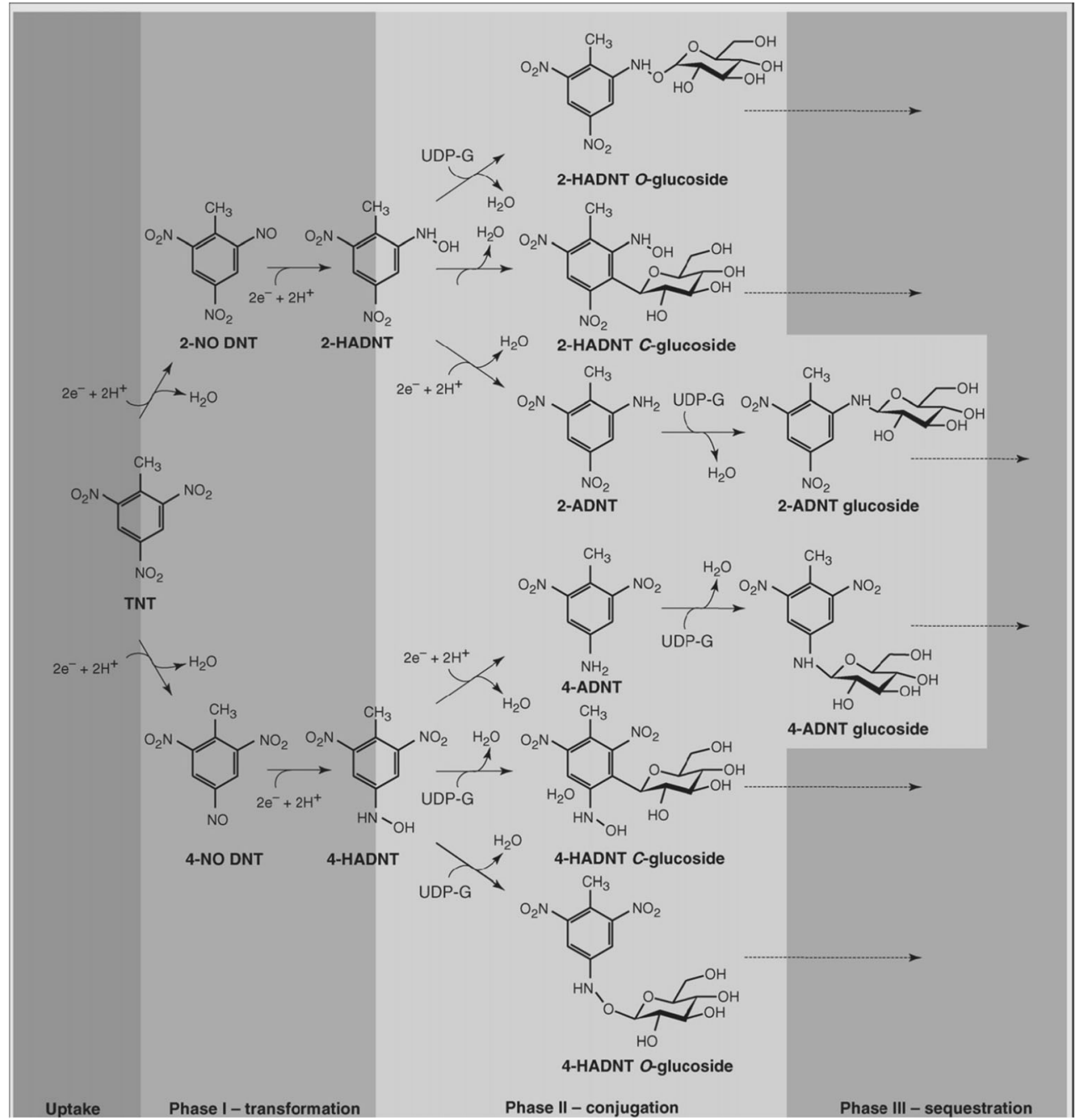

known for increasing TNT resistance in other plants $[4,36$, 37]. A more recent discovery came from the cytosol of root cells in soybean, which contain an NADPH-dependent nitroreductase. This particular nitroreductase was noted for being non-specific as well as for having shared qualities with the soluble monooxygenase system, an NADPH-dependent P450 with a fused nitroreductase partner. These similarities present the potential of this nitroreductase having activity for transforming TNT. It has also been reported that electron donors (i.e., NADH, NADPH) enhance the reductive transformation of TNT, while the electron acceptors inhibit such transformation [21].

Multiple sources have indicated that microorganisms are also capable of reductive transformation both under aerobic and anaerobic conditions. An FMN-containing nitroreductase, encoded by the $n f S I$ gene has been identified for the reductive transformation of TNT to HADNT intermediates under aerobic conditions [4]. There are a number of bacteria and fungi with that can remove the nitro groups from TNT as nitrite $\left(\mathrm{NO}_{2}{ }^{-}\right)$which enter into the nitrogen cycle [21]. This would include bacteria such as Enterobacter cloacae strain PB2, Pseudomonas putida [4], and Pseudomonas (sp.) strain JLR11 [21]. Strain JLR11 in particular is known for integrating large amounts of the nitrogen from TNT into its own organic molecules [21]. It has been noted in this case that TNT functions as the final electron acceptor in place of oxygen during cellular respiration. In addition, fungi such as the white rot fungus, Phanerochaete chrysosporium are known for reducing TNT metabolites for use as extracellular substrates of lignin-degrading enzymes [21].

The phase II conjugations in plants were suggested in earlier studies. Axenic root tissue cultures from Catharanthus roseus showed evidence of four ADNT conjugates derived from TNT. It was determined that the conjugates were formed at the amino groups, with further support coming from the presence of 6-carbon structures in the intracellular space that were involved in the conjugation [38]. This process has become well-defined in more recent studies which have identified carbohydrates and glutathione for their involvement. In Nicotiana tabacum (tobacco) strain BY2 cell suspension 
cultures, monosaccharides such as glucose were identified as common conjugates. This occurs through a glycosidic bond, which was thought to form at the nitroso group in the case of HADNTs [33, 34, 39] (Fig. 1).

In the case of tobacco, it was assumed that glycosyltransferases were responsible for catalyzing the conjugation reactions. Since then both uridine diphosphate (UDP)-glycosyltransferases and glutathione-S-transferases (GSTs) have been implicated for their involvement in this process. Microarray analysis in Arabidopsis identified seven UDP-glycosyltransferases, which upon characterization were found to conjugate HADNTs, and even ADNTs to some degree [37]. An interesting observation was the formation of $O$ - and $C$-glycosidic bonds, in addition to a predisposition of each enzyme for the 2- or 4-HADNT isomers [37].

In addition to glycosyltransferases, the upregulation of GST in Arabidopsis [36, 37] indicate an association in TNT detoxification. This has been further supported by the upregulation of GSTs in poplar, Populus trichocarpa [40], though the conjugates were not identified. A more recent study reevaluated Arabidopsis through microarray analysis and identified a number of glycosyltransferases in the conjugation process, yet there was no evidence of GSTs [41]. Collectively, the results do not indicate the involvement of glutathione conjugates. However, glutathione conjugates were identified in a recent study investigating the GSTs, GSTU24, and GSTU25 [42]. These GSTs were chosen for their high activity to TNT and were studied in transgenic Arabidopsis. One of the three processes reported was the direct conjugation of TNT through nucleophilic substitution of the nitro group to form 2glutathionyl-4,6-dinitrotoluene. The other two products were $C$-glutathionylated HADNT isomers at the methyl group of TNT [42] (Fig. 1).

In the final phase of TNT detoxification, the conjugated products are sequestered. Research into the fate of these conjugates has suggested that they are compartmentalized in vacuoles and lignin components of the secondary cell wall. Investigation in Arabidopsis using SAGE [36] identified a number of genes involved in lignin biosynthesis, including cinnamate 4-hydroxylases, 4-coumarate coenzyme A ligases, caffeic acid $O$-methyltransferases, and cinnamyl alcohol dehydrogenase to name a few [43]. Transporter proteins such as ATPbinding cassette $(\mathrm{ABC})$ transporters have been identified for their involvement in TNT detoxification [41, 44]. These are transmembrane proteins that utilize ATP hydrolysis for the translocation of compounds, such as TNT-derived conjugates, across the cellular membrane so that they may leave the cytosol. Three particular ABC transporters were identified in the shoot tissues of Arabidopsis, including the P-glycoproteins 21 and 19, as well as ATABC1. The P-glycoproteins are known for their facilitation of translocation across the membrane, while ATABC1 is a member of subfamily proteins known for bringing together iron-sulfur clusters [44].
Along with transporters, proteins involved in cell wall modification and hydrolysis were also identified [44]. Proteins involved in loosening of the cell wall, such as expansin A1, a cell wall modifier; Touch 4 which responds to environmental signals; as well as a glycoside hydrolase $\alpha$-xylosidase 1 were upregulated in shoot. In the root, $\beta$-xylosidase 2 , which is similar to $\alpha$-xylosidase 1 was upregulated. Xyloglucan endotransglucosylase/hydrolase 9, which loosens and rearranges the cell wall by way of cleaving xyloglucan chains was upregulated in roots. Some of these proteins could potentially be involved in conjugate polymerization prior to their incorporation into the cell wall [44]. The upregulation of proteins involved in lignin biosynthesis, along with the cell wall modifiers and hydrolyzing enzymes offers strong supporting evidence to the compartmentalization of conjugates within the cell wall of plant tissues.

\section{Metabolism of RDX}

Although TNT is metabolized in plant cells largely by reductive transformation, less is known about the pathways involved in RDX metabolism. As RDX can be readily taken up by plant roots, and plants are generally deficient in their ability to breakdown the ring structure, RDX can become available in the food chain through translocation to the aerial portions of the plant, or it can simply return to the environment [4]. Proposed pathways for RDX metabolism include reductive transformation, denitration, and direct photolysis $[4,8]$ (Fig. 2). Through reductive transformation, RDX can be reduced in plants to form hexahydro-1-nitroso-3,5-dinitro-1,3, 5-triazine (MNX) and further reduced to hexahydro-1,3nitroso-5-nitro-1,3,5-triazine (DNX) [8]. RDX, MXN, and DNX can undergo photolysis to form smaller metabolites such as formaldehyde and methanol. Light-independent transformation of these metabolites can produce $\mathrm{CO}_{2}$. There have also been suggestions of formaldehyde conjugation to form compounds such as $S$-formyl-glutathione [8] (Fig. 2).

There are a number of microorganisms that are known for their ability to breakdown the ring structure of RDX and use it as a source of nitrogen [4]. This occurs through denitration by a well-known enzyme, a flavodoxin-cytochrome P450. Research has shown that under anaerobic conditions, methylenedinitramine (MEDINA) is produced along with one mole of $\mathrm{NO}_{2}{ }^{-}$and two of formaldehyde. Meanwhile, under aerobic conditions 4-nitro-2,4-diazabutanal (NDAB) is produced with two moles of $\mathrm{NO}_{2}{ }^{-}$and one of formaldehyde [4]. Microbes such as the previously mentioned white rot fungus and various strains of rhodococcal bacteria have demonstrated the aerobic breakdown of RDX [45]. These bacteria would include Rhodococcus rhodochrous strain $11 \mathrm{Y}$ from the UK, Rhodococcus (sp.) strain DN228 from Australia, and Rhodococcus (sp.) strain YH1 from Israel [46]. 
Fig. 2 Proposed degradation pathways for RDX in microorganisms and plants. a Microbial degradation by the XPIA-encoded P450, beginning with denitration of the ring structure. This is followed by ring cleavage at sites $(i)$ and (ii) under anaerobic conditions to form MEDINA, or at sites (ii) and (iii) under aerobic conditions to form $\mathrm{NDAB}$, along with varying quantities of $\mathrm{NO}_{2}$ and formaldehyde. b Degradation by poplar can begin with subsequent reductions of RDX to form MNX and DNX, respectively. These compounds (RDX, MNX, and DNX) can undergo lightmediated breakdown to form formaldehyde and methanol, which can subsequently be used to form $\mathrm{CO}_{2}$. (From Rylott and Bruce 2009 [4])

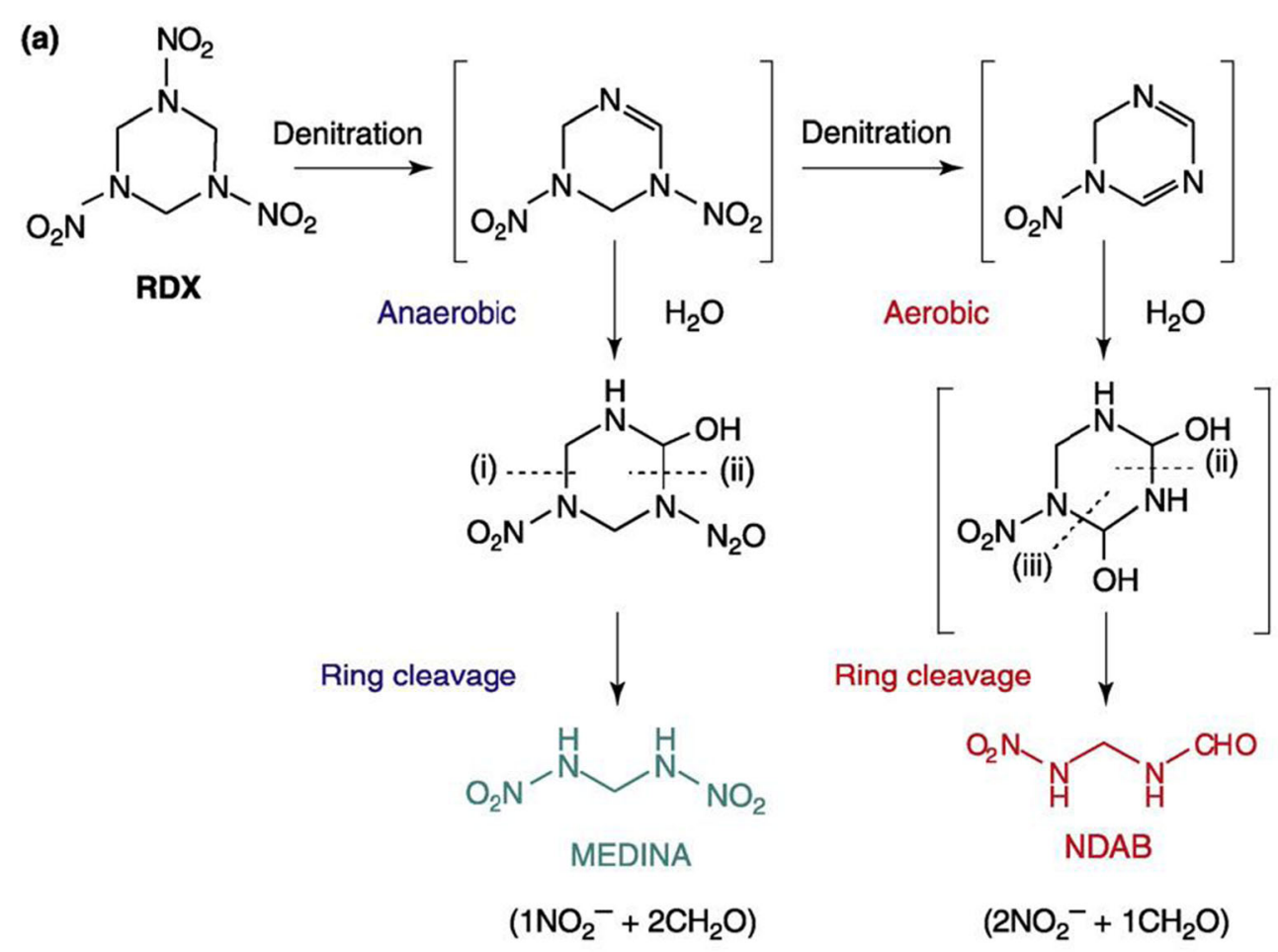

(b)

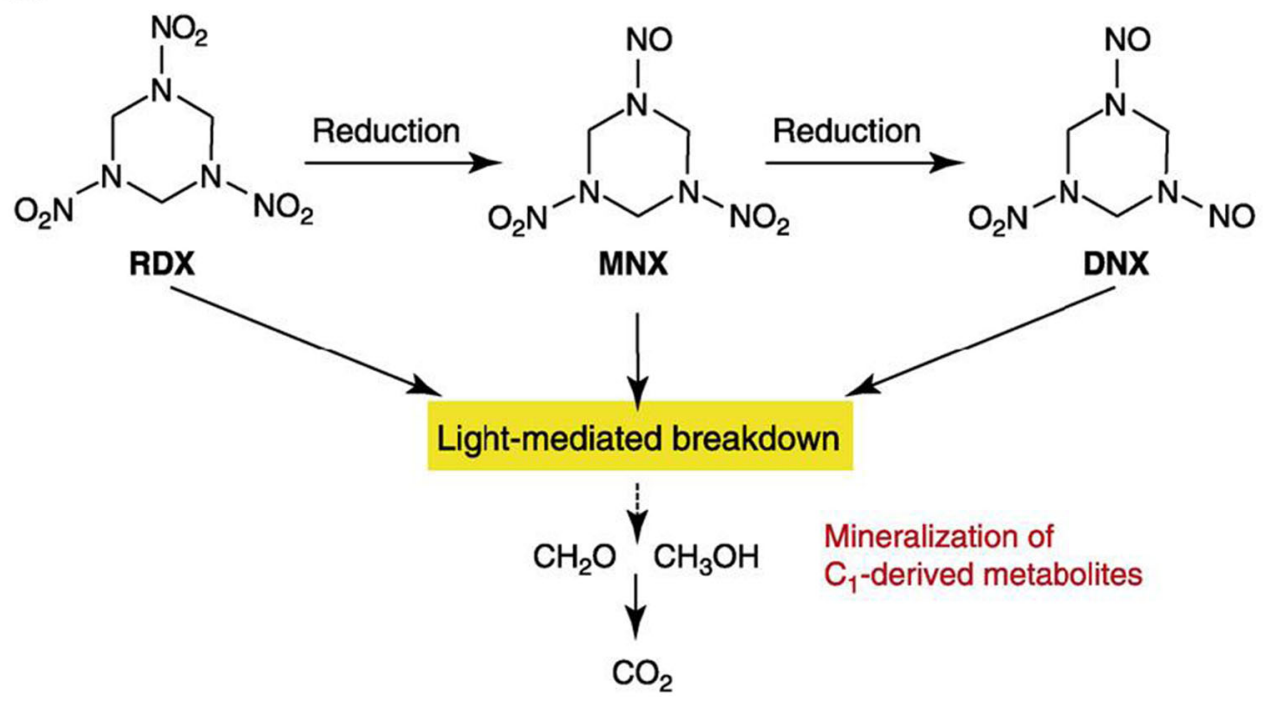

$\overline{\text { TRENDS in Biotechnology }}$

\section{Biotechnological Enhancement of TNT and RDX Phytoremediation}

Since a number of plant species have been identified for their potential in the phytoremediation of explosives, along with the elucidation of the metabolic pathways involved in explosive detoxification, the next step would be to work toward using this knowledge for field applications. The overall limitations in plants for detoxifying explosive compounds have led to extensive research into genetic engineering and microbeassisted remediation. Several researchers have indicated that the detoxification rates of explosives are ubiquitously lower in plants when compared to microbes [4]. One strategy to enhance plant degradation of explosives would be to introduce microbial genes involved in detoxification into the plant genome. Well-researched enzymes in explosive-related transgenic studies include the $n f s I$-encoded nitroreductase, the fused flavodoxin-cytochrome P450, as well as the onr- 
encoded pentaerythritol tetranitrate (PETN) reductase. Major shortcomings in using transgenics for remediation include the lack of transformation techniques suitable for certain viable candidates. Given that these techniques have been well established in tobacco and Arabidopsis, these two plants have maintained the focus of transgenic research, while these plants are not the best candidates for field applications. In addition, there are legal restrictions and public opposition in a number of countries against using transgenic plants in the environment [47].

Another approach would be to use plant root-associated bacteria to enhance detoxification of explosives. Very few studies have used rhizobacteria for the phytoremediation of explosives. Methylobacterium (sp.) strain BJ001, an endophyte of hybrid poplar (Populus deltoides/Populus nigra) strain DN34 was shown to produce $\mathrm{CO}_{2}$ from a $60 \%$ degradation of RDX and HMX [48]. Rhizobium tropici, an endophyte of hybrid poplar (P. trichocarpa/P. deltoides) strain PTD1 was reported for enhanced uptake of RDX $[6,49]$.

\section{Biotechnological Enhancement of TNT Phytoremediation}

Genetically modified plants have been a major area of focus in the phytoremediation of explosives. Research has shown that transgenic plants, when expressing the genes responsible for the degradation of nitroaromatic compounds are more capable for removing the contaminants and are also more tolerant to their toxic effects. Since microorganisms are limited by their low biomass and plants are often inadequate in terms of tolerance and degradation capability, transgenic technology offers a promising route for TNT phytoremediation. An interesting case involves the onr-encoded, FMN-containing enzyme PETN reductase, from Enterobacter cloacae strain PB2 which has been known to use pentaerythritol tetranitrate (PETN) and glycerol trinitrate or nitroglycerin (GTN) as sole sources of nitrogen. This monomeric reductase has a molecular weight of $40 \mathrm{kDa}$ and is nicotinamide coenzyme-dependent of NADPH [45]. Transformed tobacco has been demonstrated to be tolerant to GTN and TNT. In addition, PETN reductase can transform TNT and has been reported as the only enzyme able to create non-toxic compounds by removing $\mathrm{NO}_{2}$ - and hydride ($\mathrm{H})$ groups from the aromatic ring. This produces hydride and dihydride Meisenheimer TNT configurations [4, 6].

Transformed tobacco with the $n f_{s} 1$-encoded nitroreductase from E. cloacae strain NCIMB10101 are known for becoming more resilient to TNT and gaining the ability to detoxify this compound [50]. These transgenic plants have shown rapid TNT uptake with low production of ADNTs and only moderate signs of toxicity at $0.25 \mathrm{mM}$ TNT. Since the authors did not detect TNT or its metabolites from these transgenic plants, it was inferred that the TNT was either transformed completely or even sequestered in a way to make it undetectable [50]. It has also been reported that this particular nitroreductase, by comparison to PETN reductase offers a higher tolerance to TNT and a faster rate of transformation [4].

Another study indicated that Arabidopsis plants transformed with 12-oxophytodienoate reductases (OPR1) isoform showed higher potential for TNT uptake and metabolism [47]. Such techniques could prove useful if coupled with the higher-tier phytoremediation candidates. More recent sources have suggested the transformation of individual plants with multiple genes for nitroaromatic compound metabolism [4, 47]. Since sites of TNT contamination often contain metabolites of the parent compound along with other nitroaromatic compounds, overexpressing multiple enzymes could prove advantageous [47].

An interesting and unique technique known as phytoruminal bioremediation involving the anaerobic microorganisms of the rumen has been reported [47]. Such microbes, isolated from sheep rumen, have shown enzymatic activity for TNT. Introducing TNT to the diet of sheep has shown a predominance of microbes associated with TNT metabolism. The essential idea is to syndicate the TNT phytoaccumulation of plants with the degradative capabilities of microbes in the rumen of grazing mammals. It has been hypothesized that the grazers would not experience complications from this level of exposure, although more extensive research in this area is warranted [47].

Other techniques have been proposed to overcome low uptake and degradation of explosives by plants, such as the use of chaotropic agents. The chaotropic agent urea was proposed to not only to increase the aqueous solubility of TNT but also to facilitate its uptake by plant root hairs [51]. Since the surface application of urea to soil is commonly used in the slow release of nitrogen for crop growth, its use in phytoremediation would not appear to present a threat to the environment. Vetiver grass has been utilized in urea-catalyzed uptake studies both under hydroponic conditions [51] as well as in greenhouse soil studies [52]. Vetiver showed a high affinity for TNT in hydroponic media, where $40 \mathrm{mg} \mathrm{L}^{-1}$ TNT took eight days to be completely removed from the media [51]. However, when treated with $0.1 \%$ urea, vetiver exhibited an initial spike in TNT uptake, followed by a slower, yet linear uptake. The authors reported $90 \%$ TNT removal by $24 \mathrm{~h}$ with the urea treatment and $60 \%$ removal without urea. TNT was not detected in plant tissue; however, degradative metabolites such as ADNTs were present, suggesting a degradation pathway [51].

More recently, vetiver has been examined under greenhouse soil conditions for chemically catalyzed TNT uptake with urea [52]. Urea was added at $1000 \mathrm{mg} \mathrm{kg}^{-1}$, which is the maximum application rate for soil health and environmental safety. It was determined over a 12-day study that TNT uptake was increased significantly following urea treatment. There was little difference observed at $40 \mathrm{mg} \mathrm{kg}^{-1}$ as treated plants removed $100 \%$ TNT while untreated removed 
$97 \%$. At concentrations of $80 \mathrm{mg} \mathrm{kg}^{-1} \mathrm{TNT}$, however, the urea-treated plants were able to remove $84 \%$ TNT within 3 days as opposed to the $39 \%$ by the untreated plants. In 12 days, the urea-treated plants removed $95 \%$ TNT, with an $84 \%$ removal for untreated plants [52]. It has been pointed out that phytoaccumulation has yet to be differentiated from microbial degradation upon the addition of chaotropic agents [47]. However, this study supports the earlier report of increased TNT uptake in the presence of urea. These results could be invaluable in the development of a field applicable system for TNT phytoremediation.

\section{Biotechnological Enhancement of RDX Phytoremediation}

For RDX phytoremediation, P450 enzymes have been examined. In general, P450s are highly induced by chemical compounds like xenobiotics [53]. Aerobic degradation of RDX has been determined in a number of microorganisms, though the $X p 1 A$-encoded fused flavodoxin-cytochrome P450 was specifically identified in the bacterium, $R$. rhodochrous strain $11 \mathrm{Y}$ [46]. Interestingly, Xp1A and its homologs could be isolated in various laboratories from strains of Rhodococcus (sp.) only when exposed to RDX. This indicates that XP1A is either highly restricted in its distribution or that it has evolved specifically in response to $\operatorname{RDX}[46,54]$.

In order to determine if the RDX-degrading abilities of $X p 1 A$ could be maintained in transgenic plants, it was introduced to Arabidopsis [46]. The transgenic plants showed no signs of toxicity following 8 weeks in concentrations of RDX up to $2000 \mathrm{mg} \mathrm{kg}^{-1}$, while the wild-type plants showed lower biomass in addition to other toxicity symptoms. Moreover, lower levels of RDX in the shoot tissues of transgenic plants would suggest degradation by $X p 1 A$. There was also indication that the nitrogen from RDX was being used for plant growth as the transgenic plants gained biomass in their root tissues [46]. Another gene, $X p 1 B$ is a reductase enzyme that transfers electrons from NADPH to the cytochrome P450 for RDX degradation [54]. Xp1A and $X p 1 B$ as a fused flavodoxin-cytochrome P450/flavodoxin reductase system could make a major impact on RDX degradation in transgenic plants. The introduction of both Xp1A and Xp1B into Arabidopsis showed enhanced degradation with a 30 -fold increase of RDX uptake in hydroponic and soil leachate studies [54].

More recent studies have attempted to create self-sufficient, artificial P450 multidomain fusion proteins similar to the P450-BM3 system from Bacillus megaterium or the P450RhF system from Rhodococcus (sp.) NCIMB 9784 [54]. The $\mathrm{P} 450-\mathrm{RhF}$ system contains a C-terminal reductase which is fused with the oxygenase domain at the $\mathrm{N}$ terminus. These fused systems are controlled by a single gene which could prove useful for RDX degradation by plants [54].

\section{Conclusions and Future Directions}

A considerable amount of information on explosive compounds, their toxicity to living organisms, and degradation pathways has been collected. In addition, elucidating the metabolic pathways involved in detoxifying these compounds has led to the identification of potential plant species for use in TNT and RDX phytoremediation, as well as candidate genes for developing transgenic plants. However, while researchers have been working on the phytoremediation of explosives for years, very few comprehensive field studies have been carried out. One major challenge with field implementation is that the remediation strategy needs to be site-specific, as TNT concentrations in contaminated military sites are extremely heterogeneous, and local environment and soil properties, etc., would be important in selecting the best candidate for phytoremediation.

Limitations in plant metabolism and their tendency to accumulate RDX in the aerial tissues present a greater challenge for phytoremediation. There are few plants with intrinsic capability for phytoaccumulation and degradation of RDX. Rice has shown the most promise out of those investigated for RDX phytoremediation. Given that there was little evidence of transformation and that the RDX was translocated majorly to the extremities of the shoot tissues, rice would almost definitely require downstream processing such as through incineration. An alternative to field studies would be transforming rice with $X p 1 A$, which may allow for degradation of RDX.

Although research on phytoremediation of explosives has come a long way, there is still much ground to be covered in terms of developing effective models for field application. Recent research has revealed promising transgenic and nontransgenic approaches, which could prove to be practical and effective for military sites. It is anticipated that further investigation and eventual implementation will lead to the development of low-cost, environmentally friendly techniques for remediating explosive-contaminated sites.

Conflict of Interest On behalf of all authors, the corresponding author states that there is no conflict of interest.

\section{References}

1. Kalderis D, Juhasz AL, Boopathy R, Comfort S. Soils contaminated with explosives: environmental fate and evaluation of state-of-the-art remediation processes (IUPAC Technical Report). Pure Appl Chem. 2011;83(7):1407-84.

2. Douglas TA, Walsh ME, Weiss CA, McGrath CJ, Trainor TP. Desorption and transformation of nitroaromatic (TNT) and nitramine (RDX and HMX) explosive residues on detonated pure mineral phases. Water Air Soil Pollut. 2012;223:2189-200.

3. Ro KS, Venugopal A, Adrian DD, Constant D, Qaisi K, Valsaraj KT, et al. Solubility of 2,4,6-trinitrotoluene (TNT) in water. J Chem Eng Data. 1996;41:758-61. 
4. Rylott EL, Bruce NC. Plants disarm soil: engineering plants for the phytoremediation of explosives. Trend Biotechnol. 2009;27(2):7381.

5. Hannink NK, Rosser SJ, Bruce NC. Phytoremediation of explosives. Crit Rev Plant Sci. 2002;21(5):511-38.

6. Doty SL. Enhancing phytoremediation through the use of transgenics and endophytes. New Phytol. 2008;179:318-33.

7. Pennington JC, Brannon JM. Environmental fate of explosives. Thermochim Acta. 2002;384:163-72.

8. Yoon JM, Oliver DJ, Shanks JV. Plant transformation pathways of energetic materials (RDX, TNT, DNTs). In: Eaglesham A, Bessin R, Trigiano R, Hardy RWT, editors. Agricultural biotechnology: beyond food and energy to health and the environment, report 17. New York: National Agricultural Biotechnology Council; 2005.

9. Rodgers JD, Bunce NJ. Treatment methods for the remediation of nitroaromatic explosives. Water Res. 2001;35(9):2101-11.

10. United States Environmental Protection Agency (2012) Technical fact sheet-2,4,6-trinitrotoluene (TNT). Office of Solid Waste and Emergency Response (5106P). EPA 505-F-11-011.

11. Agency for Toxic Substances and Disease Registry (1995) Toxicological profile for 2,4,6-trinitrotoluene. Atlanta, GA.

12. United States Environmental Protection Agency. Integrated risk information system (IRIS). Drinking water health advisory for 2,4dinitrotoluene and 2,6-dinitrotoluene. Washington: EPA; 2008.

13. Agency for Toxic Substances and Disease Registry (1995) Toxicological profile for 1,3-dinitrobenzene and 1,3,5trinitrobenzene. Atlanta, GA.

14. Rocheleau S, Kuperman RG, Martel M, Paquet L, Bardai G, Wong S, et al. Phytotoxicity of nitroaromatic energetic compounds freshly amended or weathered and ages in sandy loam soil. Chemosphere. 2006;62(4):545-58.

15. United States Army Center for Health Promotion and Preventive Medicine (2005) Wildlife toxicity assessment for 2-amino-4,6dinitrotoluene and 4-amino-2,6-dinitrotoluene.

16. Rosser SJ, French CE, Bruce NC. Engineering plants for the phytoremediation of explosives. In-vitro cell. Dev Biol Plant. 2001;37:330-3.

17. Brannon JM, Pennington JC (2002) Environmental fate and transport process descriptors for explosives; Technical Report TR-02-10, U.S. Army Corps Eng. ERDC, Vicksburg, MS. http://el.erdc.usace.army. mil/elpubs/pdf/tre102-10.pdf

18. Singh N, Berns AE, Hennecke D, Hoener J, Koerdel W, Scheffer A. Effect of soil organic matter chemistry on sorption of trinitrotoluene and 2,4-dinitrotoluene. J Hazard Mater. 2010;173:343-8.

19. Alavi G, Chung M, Lichwa J, D'Alessio M, Ray C. The fate and transport of RDX, HMX, TNTand DNT in the volcanic soils of Hawaii: a laboratory and modelling study. J Hazard Mater. 2011;185:1600-4

20. Charles SM, Teppen BJ, Li H, Laird DA, Boyd SA. Exchangeable cation hydration properties strongly influence soil sorption of nitroaromatic compounds. Soil Sci Soc Am J. 2006;70:1470-9.

21. Adamia G, Ghoghoberidze M, Graves D, Khatisashvili G, Kvesitadze G, Lomidze E, et al. Absorption, distribution, and transformation of TNT in higher plants. Ecotoxicol Environ Saf. 2006;64: 136-45.

22. Hughes JB, Shanks J, Vanderford M, Lauritzen J, Bhadra R. Transformation of TNT by aquatic plants and plant tissue cultures. Environ Sci Technol. 1997;31(1):266-71.

23. Makris KC, Shakya KM, Datta R, Sarkar D, Pachanoor D. High uptake of 2,4,6-trinitrotoluene by vetiver grass - potential for phytoremediation? Environ Pollut. 2007;146:1-4.

24. Pavlostathis SG, Comstock KK, Jacobson ME, Saunders FM. Transformation of 2,4,6-trinitrotoluene by the aquatic plant Myriophyllum spicatum. Environ Toxicol Chem. 1998;17(11): 2266-73.
25. Vila M, Mehier S, Lorber-Pascal S, Laurent F. Phytotoxicity to and uptake of RDX by rice. Environ Pollut. 2007;145:813-7.

26. Best EPH, Zappi ME, Fredrickson HL, Sprecher SL, Larson SL, Ochman M. Screening of aquatic and wetland plant species for phytoremediation of explosive-contaminated groundwater from the Iowa Army Ammunition Plant. Ann N Y Acad Sci. 1997;829:17994.

27. Scheidemann P, Klunk A, Sens C, Werner D. Species dependent uptake and tolerance of nitroaromatic compounds by higher plants. J Plant Physiol. 1998;152:242-7.

28. Dalton PA, Smith RJ, Truong PNV. Vetiver grass hedges for erosion control on a cropped flood plain: Hedge hydraulics. Agric Water Manag. 1996;31:91-104.

29. Andra SS, Datta R, Sarkar D, Makris KC, Mullens CP, Sahi SV, et al. Induction of lead-binding phytochelatins in vetiver grass [Vetiveria zizanioides (L.)]. J Environ Qual. 2009;38:868-77.

30. Chiu KK, Ye ZH, Wong MH. Enhanced uptake of As, Zn, and Cu by Vetiveria zizanioides and Zea mays using chelating agents. Chemosphere. 2005;60:1365-75.

31. Brandt R, Merkl N, Schultze-Kraft R, Infante C, Broll G. Potential of vetiver (Vetiveria zizanioides (L.) Nash) for phytoremediation of petroleum hydrocarbon-contaminated soils in Venezuela. Int $\mathrm{J}$ Phytorem. 2006;8(4):273-84.

32. Burken JG, Schnoor JL. Uptake and metabolism of atrazine by poplar trees. Environ Sci Technol. 1997;31(5):1399-406.

33. Wang C, Lyon DY, Hughes JB, Bennett GN. Role of hydroxylamine intermediates in the phytotransformation of 2,4,6-trinitrotoluene by Myriophyllum aquaticum. Environ Sci Technol. 2003;37(16):3595600.

34. Subramanian M, Oliver DJ, Shanks JV. TNT phytotransformation pathway characteristics in Arabidopsis: role of aromatic hydroxylamines. Biotechnol Prog. 2006;22(1):208-16.

35. Bhadra R, Spanggord RJ, Wayment DG, Hughes JB, Shanks JV. Characterization of oxidation products of TNT metabolism in aquatic phytoremediation systems of Myriophyllum aquaticum. Environ Sci Technol. 1999;33(19):3354-61.

36. Ekman DR, Lorenz WW, Przybyla AE, Wolfe NL, Dean JFD. SAGE analysis of transcriptome responses in Arabidopsis roots exposed to 2,4,6-trinitrotoluene. Plant Physiol. 2003;133(3):1397-406.

37. Gandia-Herrero F, Lorenz A, Larson T, Graham IA, Bowles DJ, Rylott EL, et al. Detoxification of the explosive 2,4,6-trinitrotoluene in Arabidopsis: discovery of bifunctional O- and Cglucosyltransferases. Plant J. 2008;56:963-74.

38. Bhadra R, Wayment DG, Hughes JB, Shanks JV. Confirmation of conjugation processes during TNT metabolism by axenic plant roots. Environ Sci Technol. 1999;33(3):446-52.

39. Vila M, Pascal-Lorber S, Rathahao E, Debrauwer L, Canlet C, Laurent F. Metabolism of [14C]-2,4,6-trinitrotoluene in tobacco cell suspension cultures. Environ Sci Technol. 2005;39(2):663-72.

40. Brentner LB, Mukherji ST, Merchie KM, Yoon JM, Schnoor JL, Aken BV. Expression of glutathione-S-transferases in poplar trees (Populus trichocarpa) exposed to 2,4,6-trinitrotoluene (TNT). Chemosphere. 2008;73:657-62.

41. Rao MR, Halfhill MD, Abercrombie LG, Ranjan P, Abercrombie JM, Gouffon JS, et al. Phytoremediation and phytosensing of chemical contaminants, RDX and TNT: identification of the required target genes. Funct Integr Genom. 2009;9:537-47.

42. Gunning V, Tzafestas K, Sparrow H, Johnston EJ, Brentnall AS, Potts JR, et al. Arabidopsis glutathione transferases u24 and U25 exhibit a range of detoxification activities with the environmental pollutant and explosive, 2,4,6-trinitrotoluene. Plant Physiol. 2014;165(2):854-65.

43. Raes J, Rohde A, Christensen JH, Van de Peer Y, Boerjan W. Genome-wide characterization of the lignification toolbox in Arabidopsis. Plant Physiol. 2003;133:1051-71. 
44. Landa P, Storchova H, Hodek J, Vankova R, Podlipna R, Marsik P, et al. Transferases and transporters mediate the detoxification and capacity to tolerate trinitrotoluene in Arabidopsis. Funct Integr Genom. 2010;10:547-59.

45. Vanek T, Gerth A, Vakrikova Z, Podlipna R, Soudek P. Phytoremediation of explosives. In: Marmiroli N, Samotokin B, Marmiroli M, editors. Advanced science technology for biological decontamination of sites affected by chemical and radiological nuclear agents, NATO Science Series Vol. 75. Dordrecht, The Netherlands: Springer; 2007.

46. Rylott EL, Jackson RG, Edwards J, Womack GL, Seth-Smith HMB, Rathbone DA, et al. An explosive-degrading cytochrome P450 activity and its targeted application for the phytoremediation of RDX. Nat Biotechnol. 2006;24(2):216-9.

47. Stenuit BA, Agathos SN. Microbial 2,4,6-trinitrotoluene degradation: could we learn from (bio)chemistry for bioremediation and vice versa? Appl Microbiol Biotechnol. 2010;88:1043-64.

48. Van Aken B et al. Biodegradation of nitro-substituted explosives 2,4, 6-trinitrotoluene, hexahydro-1,3,5-trinitro-1,3,5-triazine, and octahydro-1,3,5,7-tetranitro-1,3,5-tetrazocine by a phytosymbiotic Methylobacterium sp. associated with poplar tissues (Populus deltoids nigra DN34). Appl Environ Microbiol. 2004;70:508-17.
49. Newman LA, Reynolds CM. Bacteria and phytoremediation: new uses for endophytic bacteria in plants. Trends Biotechnol. 2005;23(1):6-8.

50. Hannink N, Rosser SJ, French CE, Basran A, Murray JAH, Nicklin $\mathrm{S}$, et al. Phytodetoxification of TNT by transgenic plants expressing a bacterial nitroreductase. Nat Biotechnol. 2001;19:1168-72.

51. Makris KC, Shakya KM, Datta R, Sarkar D, Pachanoor D. Chemically catalyzed uptake of 2,4,6-trinitrotoluene by Vetiveria zizanioides. Environ Pollut. 2007;148:101-6.

52. Das P, Datta R, Makris KC, Sarkar D. Vetiver grass is capable of removing TNT from soil in the presence of urea. Environ Pollut. 2010;158:1980-3.

53. Robineau T, Batard Y, Nedelkina S, Cabello-Hurtado F, LeRet M, Sorokine O, et al. The chemically inducible plant cytochrome $\mathrm{P} 450$ CYP76B1 actively metabolizes phenylureas and other xenobiotics. Plant Physiol. 1998;118:1049-56.

54. Rylott EL, Jackson RG, Sabbadin F, Seth-Smith HMB, Edwards J, Chong CS, et al. The explosive-degrading cytochrome P450 Xp1A: biochemistry, structural features and prospects for bioremediation. Biochim Biophys Acta. 2011;1814(1):230-6. 